BRANCHER, Ana; LOHN, Reinaldo L. Histórias na ditadura: Santa Catarina (1964-1985). Florianópolis: Ed. da UFSC, 2014.

\title{
Para além da historiografia sobre a Ditadura em Santa Catarina (1964-1985)
}

\section{Besides the historiography on the Dictatorship in Santa Catarina} (1964-1985)

\section{Yomara Feitosa C. de Oliveira Fagionato ${ }^{\mathrm{I}}$}

O livro "Histórias na ditadura: Santa Catarina, 1964-1985", organizado por Ana Brancher e Reinaldo Lohn, demonstra a pertinência e atualidade da publicação da obra, vista através dos diversos temas abordados sobre o golpe de 1964 e o período ditatorial. Obra composta por quatorze artigos escrita por dezenove autores denotam a amplitude do trabalho historiográfico, tanto pela variedade das abordagens quanto pela riqueza das temáticas e/ou pelo uso de fontes sobre o período.

Há um destaque especial quando à leitura deste livro, pois esta convida a pensar para além da temporalidade enunciada em seu título, ao explorar as peças de uma "cultura política autoritária", assim um dos organizadores, Reinaldo Lohn, em seu artigo de abertura da coletânea intitulado: "Relações políticas e ditadura: do consórcio autoritário à transição controlada" realiza um instigante panorama regional sobre o golpe de 1964 em Santa Catarina, ao mesmo tempo em que coloca sua narrativa sobre a ditadura deste Estado em escala nacional, ao abordar os diversos atores políticos atuantes durantes os anos subsequentes ao golpe de 1964, ao explorar o que foi o denominado "consórcio entre estado e as empresas privadas", para apresentar uma das análises ao enunciar aos leitores as diversas "marcas de uma transição para a democracia que não

\footnotetext{
I Doutoranda do Programa de Pós-graduação em História do Tempo Presente (PPGH), na Universidade do Estado de Santa Catarina - UDESC. Bolsista da Capes. E-mail: yocaetano@hotmail.com
} 
rompeu com uma estrutura de poder incrustadas nas redes sociais e que resiste à democratização." II

No segundo texto da coletânea, Diego Pacheco apresenta um mapa histórico e geográfico da formação regional com ligações nacionais do denominado "Grupos dos Onze", quando enuncia a ligação estreita entre estes e o Partido Comunista Brasileiro (PCB), todavia, ao analisar os diferentes Grupos dos Onze catarinenses não se podem afirmar ligação entre eles no Estado. Através de fontes da imprensa alternativa interpreta que os Grupos dos Onze "surgiram como uma resposta ao receio de um golpe contra o governo legalmente constituído", assim faz uma reflexão importante, ao retomar o contexto da década de 1960, para compreender as reformas debatidas e defendidas por estes grupos, que foram paralisadas devido à violência e legitimação do estado de exceção brasileiro, quando derrotou e usurpou, tanto os Grupos dos Onze, como toda uma história democrática porvir.

A historiadora Cristina Ferreira, em seu artigo: "Mundos do trabalho e regime autoritário: simbologia das celebrações e manifestações públicas no Primeiro de maio" mergulha nos mundos do trabalho para visualizar através das formas de sociabilidade, como na simbolização da celebração pública de Primeiro de Maio, apresenta um quadro político, no qual o resultado foi perda de direitos dos trabalhadores.

Os autores do artigo intitulado: "Indigenismo e movimento indigena Xokleng, Kaingang e Guarani”, consistem em um profundo e sensível debate acerca das políticas indigenistas nacionais destes povos durante os "anos de chumbo", e, soma uma denúncia à escassez e dificuldade em obter fontes e informações acerca da temática. Na mesma ponta do debate, e também com dificuldade de acesso a fontes e a literatura sobre o tema, a questão racial no Brasil e em Santa Catarina foi abordada no artigo intitulado: "Movimento antirracismo e a ditadura militar: militantes negros em Santa Catarina", de João Carlos Nogueira, quando analisa apesar do controle opressivo intenso sobre os movimentos negros ocorreram resistências à ditadura, assim o autor levanta histórias sobre militantes, e cita intelectuais pertencentes ao movimento negro nacional e estadual.

\footnotetext{
" BRANCHER, Ana; LOHN, Reinaldo L. Histórias na ditadura: Santa Catarina (19641985). Florianópolis: Ed. da UFSC, 2014. p. 55.
} 
As autoras do artigo intitulado: "Gênero e militância de esquerda", mobilizam as relações de gênero em relação às estratégias de resistência ao Estado autoritário. Já no artigo intitulado: "Políticas sociais para infância e juventude carente e infratora (1970-1980)", as autoras no título enunciam suas preocupações em analisar, durante o contexto autoritário políticas públicas voltadas à infância e juventude, para refletir o quanto temos de permanência das "irregularidades históricas de violência perpetradas contra os "menores" que se encontravam abrigados nessas instituições, mantidas pelos órgãos públicos." "III A Fundação Nacional para o Bem-Estar do menor (FUNABEM), aliada a política Nacional de menores e o Código de Menores de 1979, foram os discursos analisados pelas historiadoras.

Outro texto, com preocupações sobre o campo da economia catarinense, o artigo intitulado: "Planejamento, crescimento econômico e desigualdades sociais”, problematizou a crença de que a industrialização e modernização das estruturas produtivas contribuiriam para o crescimento social, trazendo nas relações autoritárias ações em favor do capital privado, promovendo as desigualdades sociais e a concentração de riquezas, inserida na modernização conservadora. Já os autores do artigo intitulado: " $O$ campo, a cidade e o lugar da natureza e do meio ambiente nos projetos desenvolvimentistas", analisaram os Planos de Metas do Governo (PLAMEG I e II) localizando os investimentos dos recursos no campo do desenvolvimento econômico, sendo uma mínima parte investida no campo da educação, cultura, justiça e segurança pública. Com enfoque analítico, os autores abordaram a ideia de "modernizar" a estrutura agrária de Santa Catarina ao longo dos anos autoritários, denotando os silenciamentos de tantas histórias prejudicas pela degradação ambiental dos rios, solo e ar, como nas enchentes tem-se exemplificados alguns dos impactos socioambientais. Outro impacto da política desenvolvimentista do período ditatorial, o artigo intitulado: "Educação: modernização, democratização do acesso e controle pedagógico", analisou o quanto educação brasileira caminhava para atender através de suas políticas públicas o plano de governo desenvolvimentista, também a educação do Estado de Santa Catarina, estava se modernizando e deveria atender ao setor industrial. Plano Estadual de Educação (1969-1980) sem inovação em relação ao primeiro, pois estavam afinados com o governo autoritário, nos quais em

\footnotetext{
III AREND, Silva M. F.; DAMINELLI, Camila Serafim. Políticas sociais para a infância e juventude carente e infratora (1970-1980). In.: BRANCHER, Ana e LOHN, Reinaldo L. (org) Histórias na ditadura: Santa Catarina: 1964-1985, Florianópolis: Ed. Da UFSC, 2014. P. 204.
} 
ambos não ocorreram participação docente "evidenciando a característica comum a todos os governadores do período, totalmente articulados com o regime ditatorial na execução de políticas públicas para a educação." IV

O jornalista Celso Martins, no artigo intitulado: "A gente quer ter voz ativa: estudantes contra a ditadura (1975-1979)", de forma consistente e com fontes articuladas sobre a temática elabora uma narrativa sobre a ação do Partido Comunista Brasileiro (PCB) na atuação de resistência dos estudantes e professores universitários do Estado.

Tendo uma pesquisa com base nos documentos produzidos no campo da Justiça Militar, o historiador Mateus Gamba Torres, autor do artigo intitulado: "A Operação Barriga Verde e as esquerdas na década de 1970”, elaborou um panorama da atuação dos operadores dos aparelhos do poder judiciário, através das análises dos discursos jurídicos militares, sobre a denominada "Operação Barriga Verde", quando os integrantes do PCB foram alvos de prisões e perseguições por parte do regime autoritário, tendo como crítica do sentido de justiça da época a cultura jurídica de que "todos eram culpados até que se provasse ao contrário".

No penúltimo, texto apresentado pela historiadora Ana Maria Veiga, autora do artigo intitulado: "Imprensa e censura nas memorais de jornalistas", temos uma refinada leitura sobre uma perspectiva da história da repressão aos meios de comunicação me Santa Catarina, ao investigar a relação entre mídia e ditadura, através de testemunhos dos profissionais envolvidos neste cotidiano, desvelou instigantes depoimentos atravessados pela autocensura, pressões, intimidações e com alguns "lampejos de liberdade", denotando as muitas facetas dos bastidores da repressão ditatorial nas mídias em Santa Catarina, sempre na relação de escala com as mídias nacionais.

No artigo que finaliza a coletânea, intitulado: "Militância nas margens: lembranças da resistência à ditadura $e$ das lutas pela democratização", Luis Felipe Falcão faz a reflexão, utilizando a história oral através do rico depoimento de Rosângela de Souza, - advogada trabalhista com atuação sindical e associações de classistas. Este artigo convida aos leitores a pensarem nas múltiplas temporalidades e sobre as

IV PAIM, Elison Antonio. Educação: modernização, democratização do acesso e controle pedagógico. In.: BRANCHER, Ana e LOHN, Reinaldo L. (org) Histórias na ditadura: Santa Catarina: 1964-1985, Florianópolis: Ed. Da UFSC, 2014. p.252. 
"gerações que se sentiram atraídas pela contestação e pelo engajamento político de esquerda entre as décadas de 1960 e 1980", e ainda, no sentido de que os desafios atuais possuem apenas contornos diversos, afinal como afirmou Rosângela de Souza, "os tempos já eram outros".

Tanto no primeiro texto, quanto no último, os leitores são convidados incessantemente a refletirem sobre temas e personagens inseridos no campo da renovação historiográfica regional, em relação constante com outras obras da historiografia atual sobre a ditadura, como demonstrado nos diferentes textos sobre os militantes negros, estudantes e/ou, sobre os denominados "militantes de esquerda", ainda, movimentos sociais e sindicais, ou são convidados a pensar sobre a temática da infância e juventude carente e infratora. Assim, a educação, o mundo do trabalho, ou o campo, a cidade e o lugar da natureza, durante os anos ditatoriais foram explorados através de perspectivas historiográficas distintas, contribuindo para ampliar o conhecimento discursivo de historiadores ou leigos. Os autores da coletânea abordaram de forma problemática os discursos enunciados na "Operação Barriga Verde", ou sobre os Grupos dos Onze, ao mesmo passo que as relações de gênero, étnico/raça, classe e geração foram abordagens recorrentes nos diferentes artigos.

Por todo cuidado teórico-metodológico e pelas análises refinadas proporcionadas aos leitores, ao destacar a complexidade das resistências dos diferentes personagens, e a amplitude do controle exercido durantes os "anos de chumbo" nos diversos níveis e capilaridades das relações com a sociedade, considera-se esta coletânea como uma referência para além da historiografia regional sobre o tempo da ditadura em Santa Catarina. 